\title{
Help-seeking by substance dependants presenting to healthcare professionals in the Free State Province
}

\author{
P M van Zyl, C A Gagiano, W F Mollentze, J S Snyman, G Joubert \\ Department of Pharmacology, Faculty of Health Sciences, University of the Free State, Bloemfontein
}

P M van Zyl, MB ChB, MMedSc (Clin Pharm), PhD

Department of Psychiatry, Faculty of Health Sciences, University of the Free State

C A Gagiano, MB ChB, MMed (Psych), MD

Department of Internal Medicine, Faculty of Health Sciences, University of the Free State

W F Mollentze, MD, FCP (SA), MMed (Int), FACE, FRCP

Department of Pharmacology, University of Pretoria (currently Agility Global Health Solutions, Johannesburg)

J S Snyman, MB ChB, MPharm Med, MD

Department of Biostatistics, Faculty of Health Sciences, University of the Free State

G Joubert, BA, MSC

Corresponding author: PM van Zyl (vzylpm@ufs.ac.za)

\begin{abstract}
Introduction. Current data regarding treatment needs in South Africa for substance dependence are based on admissions to specialised treatment centres. The data therefore do not include patients presenting to independent healthcare workers and state hospitals.

Aim. The aim of this study was to investigate help-seeking behaviour for substance dependence disorders from the perspective of healthcare professionals at various levels of the referral chain in the Free State Province.
\end{abstract}

Design. A descriptive study was performed.

Setting. Treatment environments in the Free State Province accessible to substance-dependent persons served as the study setting.

Participants. General practitioners, private psychiatrists, prescribing healthcare professionals at state hospitals and treatment centres, and non-prescribing therapists responsible for the management of substance-dependent persons, were considered for participation.

Measurements. A questionnaire was used to determine the level of help-seeking experienced by the participants regarding various classes of psycho-active substances.

Findings. The presentation of alcohol, cannabis, opioid, benzodiazepine, ecstasy, cocaine and inhalant dependency at general practitioners, private psychiatrists, treatment centres and non-prescribing therapists was compared. Different patterns of helpseeking for substance dependence from the various professional groups were detected. Regarding alcohol dependence, $40.3 \%$ of private general medical practitioners reported being confronted with alcohol dependence at least once per month, compared with $100 \%$ of treatment centre representatives and private psychiatrists, $70.6 \%$ of state hospitals and $53.8 \%$ of non-prescribers. State hospitals reported the highest frequency for contact with cases of cannabis dependence, compared with the other professional groups, while psychiatrists reported the highest contact with cases involving benzodiazepine, cocaine and ecstasy. Therapists reported a higher level of contact with inhalant dependence, while this group virtually never presented at general practitioners and private psychiatrists.

Conclusion. Help-seeking data can be used in conjunction with other data, such as treatment demand data, to inform and adapt policies and practice. Variations in the manifestation of help-seeking behaviour at various groups may be important pointers to conditions that influence help-seeking, and should therefore be investigated further.

SAfr J Psych 2012;18(3):96-102. DOI:10.7196/SAJP.352

Substance dependence is a physical condition that manifests via substance abuse. The perception of substance dependence 
consequently often includes the rather difficult-to-define and fluctuating activity of regular substance abuse. Furthermore, social stigmatisation and issues of legality often cause it to be practised in privacy. The condition, therefore, does not lend itself to easy measuring.

The geographic centrality within South Africa of the Free State Province causes it to be at the confluence of roads connecting the country's major centres. It also forms a major centre for trade with Lesotho, where the production of cannabis is one of the main sources of revenue.' These factors can reasonably be expected to have implications for the local distribution of substances of abuse and the prevalence of substance dependence. The most comprehensive data available for substance dependence in the Free State are for alcohol dependence. A population assessment by the South African Demographic and Health Survey (SADHS) ${ }^{2}$ showed a particularly high prevalence of alcohol dependence among the Free State adult population (34\% of all males, $10 \%$ of all females). Treatment demand figures obtained by Plüddemann et al. ${ }^{3}$ reflect admissions to specialised treatment centres registered at the Department of Social Development. Comparison of the datasets from the aforementioned 2 surveys suggests a large treatment need $v$. treatment demand gap. However, cases treated by private general practitioners, private psychiatrists and state hospitals are not reflected. ${ }^{3}$ It is well known that the majority of substance-dependent individuals do not seek treatment for their dependence, ${ }_{4}^{4}$ partly because of poor experiences and perceptions of treatment systems. From a service delivery viewpoint, it is therefore important to gain a clearer picture of the patient treatment interface in substance dependence.

The opportunity for recording unmeasured entities of real treatment demand occurs with help-seeking, when the dependence comes to the attention of a professional, somewhere on the timespan between observer-perceived need and actual treatment. Stateprovided health services in the province comprise 3 discrete health complexes, each providing different levels of services. The organisation guides the level of service provided as well as referrals in a particular region. In the case of the Free State Province, the 3 health complexes represent different sets of substance abuse and designated services:

1. The Southern Health Complex has a strong urban centre that provides the widest range of services in state institutions and several specialists in the private sector. Medical care to substancedependent persons is concentrated in some state hospitals for state patients. In the case of private patients, dual-diagnosis patients are managed by psychiatrists and primary substance dependence by an inpatient rehabilitation facility. This facility serves as a referral centre for the whole province.

2. The Northern Health Complex has outpatient treatment facilities in 2 locations in the private sector, with 1 inpatient state psychiatric facility and only 1 private psychiatrist. Medical services are therefore rendered by general practitioners (GPs), relying on consultation with the psychiatrist or other specialists.
3. The Eastern Health Complex is the most rural in character, with no dedicated services in the private sector and one inpatient psychiatric facility in the public sector. Medical services are rendered by general practitioners, often referring to institutions outside the province in complicated cases.

The aim of this study was to determine the frequency of exposure of various groups of healthcare professionals to help-seeking behaviour involving dependence on a range of substances, where help-seeking is defined as consultation for a problem that is related to dependence according to the health professional's opinion.

\section{Methods}

A multi-level descriptive study was performed. The study population comprised healthcare workers and allied health professionals providing treatment services for substance dependence in an individual capacity or who were employed by an institution in the Free State Province.

\section{Selection of private GPs}

To guide the selection of private GPs and ensure a geographically representative sample, the province was first divided into the 3 existing health complexes (service delivery units), and then into study environments according to the level of state healthcare services in the particular geographical area. A list of study environments was compiled from regional and facility information obtained from the provincial government website (http://www.fshealth.gov.za) and the Provincial Head Office. Five regional environments, defined as the area within a $20 \mathrm{~km}$ radius of a town with a regional state hospital, were identified, and all were included in the study.

Twenty district environments, defined as the area within a radius of $20 \mathrm{~km}$ of a town with a district state hospital (outside a regional environment), and 38 basic environments, defined as towns outside a radius of $20 \mathrm{~km}$ from a town with a regional or district hospital, were identified. For each category, the names of the towns were arranged alphabetically and a random selection was made using random number tables. ${ }^{5}$ Five district environments and 6 basic environments were selected in this way.

To mimic a real-life situation, a database containing the names of private GPs who identified themselves as such was compiled from the Telkom telephone directory for 2004/2005. Names were arranged alphabetically within the respective geographic categories and numbered. A random selection was made using random number tables. ${ }^{5}$ Ten private GPs per regional environment, up to 5 private GPs per selected district environment, and up to 5 private GPs per selected basic environment, were selected. If a randomly selected participant declined, could not comply with the appointment schedule after 3 attempts, or had closed down practice, a replacement was selected as follows: if the person recommended an alternative participant from his/her own practice, this person was used, provided that her/his name did not appear 
on the original name list; if there was no such nomination, a replacement was drawn by random selection from the remainder of the original list; if the practice had been taken over by another practitioner, the latter was assumed as the replacement.

In total, 123 names were drawn, 30 were excluded on the grounds of not being practicing GPs, 14 declined and 2 were excluded after repeated appointments were missed. The remaining 77 private GPS participated in the study.

\section{Selection of private psychiatrists}

All private psychiatrists indicated as such in the Telkom telephone directory for 2004/2005 were contacted. One psychiatrist declined, 1 had emigrated, and 1 who had opened a practice recently was added on the recommendation of fellow psychiatrists. A total of 11 private psychiatrists participated.

\section{Selection of prescribers from state hospitals and treatment centres}

Convenience sampling was used to select prescribers from state hospitals and treatment centres and non-prescribers with significant involvement in the treatment of dependent persons. In the state hospitals, 17 prescribing representatives (1 per selected hospital) were selected on the basis of being personally designated to provide medical treatment for substance dependence, or as a representative of a designated department as recommended by the Head of Clinical Services of the particular institution. This group consisted of 10 full-time medical officers, 3 specialist physicians, 1 family physician and 3 psychiatrists.

All persons involved in selecting pharmacotherapy in treatment centres, 2 part-time medical officers (working in the same centre) and a professional nurse (from another centre) were included.

\section{Selection of non-prescribing therapists}

A group of non-prescribers were selected on the grounds of their involvement in a treatment centre or spontaneous nomination by other participants as significant role players. Eleven psychologists and 2 social workers participated in the study.

All questionnaires were administered by the researcher during an interview. The questionnaire (available in Afrikaans and English) was tested in a pilot study conducted with 3 randomly selected private GPs not included in the study population. Participants were assured that data reporting would be anonymous and that they could not gain anything from giving false information. They were not influenced to provide 'correct' answers or briefed on expected outcomes. To promote a positive attitude towards the research process, care was taken to respect time schedules.

\section{Data collection and analysis}

Participants were asked to indicate their exposure to 'helpseeking'for dependence-related health problems, involving several categories of substances. Responses were grouped as follows: (i) never - the respondent indicated that he/she had no exposure to help-seeking behaviour; (ii) low - occasional exposure, less than once per month; and (iii) high - at least one exposure per month.

Following the completion of the questionnaire, a structured interview was conducted, tape-recorded and transcribed. The results of a selected section of the questionnaire are reported in this paper.

The Department of Biostatistics of the University of the Free State was involved in data analysis. The contents of the completed questionnaires were coded. Categorical variables were summarised by frequencies and percentages and numerical variables by means, standard deviations or percentiles.

\section{Ethical considerations}

The research proposal was approved by the Ethics Committee of the Faculty of Health Sciences, University of the Free State. Written permission was obtained from the relevant hospitals' management, Human Resources of the Department of Health, and individual participants. Confidentiality was maintained throughout. The interview transcriber was not informed of participant identities, and the need for confidentiality was emphasised. Individual names and places were not reflected in the final report.

\section{Results}

\section{Demographic information}

The study population consisted of 121 participants, which included 77 GPs, 3 representatives of treatment centres, 11 private psychiatrists and 17 state hospital representatives. Thirteen nonprescribing therapists were also included. The group had a high level of experience, with a mean experience of 22.3 years (SD \pm 11.1

Table 1. Frequency of help-seeking for alcohol dependence at different groups of professional healthcare practitioners

\begin{tabular}{|c|c|c|c|c|c|}
\hline \multirow[b]{2}{*}{ Frequency } & \multicolumn{5}{|c|}{ Groups of professional practitioners } \\
\hline & $\begin{array}{l}\text { General practitioners } \\
(n=77)\end{array}$ & $\begin{array}{l}\text { Treatment centres } \\
(n=3)\end{array}$ & $\begin{array}{l}\text { Private psychiatrists } \\
(n=11)\end{array}$ & $\begin{array}{l}\text { State hospitals } \\
(n=17)\end{array}$ & $\begin{array}{l}\text { Non-prescribers } \\
(n=13)\end{array}$ \\
\hline Never & $3(3.9 \%)$ & $0(0 \%)$ & $0(0 \%)$ & $3(17.6 \%)$ & $1(7.7 \%)$ \\
\hline <once a month & $43(55.8 \%)$ & $0(0 \%)$ & $0(0 \%)$ & $2(11.8 \%)$ & $5(38.5 \%)$ \\
\hline zonce a month & $31(40.3 \%)$ & $3(100 \%)$ & $11(100 \%)$ & $12(70.6 \%)$ & $7(53.8 \%)$ \\
\hline
\end{tabular}


Table 2. Frequency of help-seeking for cannabis dependence at different groups of professional healthcare practitioners

\begin{tabular}{llllll}
\hline & \multicolumn{5}{c}{ Groups of professional practitioners } \\
\cline { 2 - 6 } Frequency & $\begin{array}{l}\text { General practitioners } \\
(\boldsymbol{n}=\mathbf{7 7 )}\end{array}$ & $\begin{array}{l}\text { Treatment centres } \\
(\boldsymbol{n}=\mathbf{3})\end{array}$ & $\begin{array}{l}\text { Private psychiatrists } \\
(\boldsymbol{n}=\mathbf{1 1 )}\end{array}$ & $\begin{array}{l}\text { State hospitals } \\
(\boldsymbol{n}=\mathbf{1 7 )}\end{array}$ & $\begin{array}{l}\text { Non-prescribers } \\
(\boldsymbol{n}=\mathbf{1 3})\end{array}$ \\
\hline Never & $30(39.0 \%)$ & $0(0 \%)$ & $0(0 \%)$ & $3(17.7 \%)$ & $4(30.8 \%)$ \\
< once per month & $38(49.4 \%)$ & $0(0 \%)$ & $3(27.3 \%)$ & $3(17.7 \%)$ & $5(38.5 \%)$ \\
zonce per month & $9(11.7 \%)$ & $3(100 \%)$ & $8(72.7 \%)$ & $11(64.7 \%)$ & $4(30.8 \%)$
\end{tabular}

Table 3. Frequency of help-seeking for OTC and prescription drug dependence at different groups of professional healthcare practitioners

\begin{tabular}{|c|c|c|c|c|c|}
\hline \multirow[b]{2}{*}{ Frequency } & \multicolumn{5}{|c|}{ Groups of professional practitioners } \\
\hline & $\begin{array}{l}\text { General practitioner } \\
(n=77)\end{array}$ & $\begin{array}{l}\text { Treatment centre } \\
(n=3)\end{array}$ & $\begin{array}{l}\text { Private psychiatrist } \\
(n=11)\end{array}$ & $\begin{array}{l}\text { State hospital } \\
(n=17)\end{array}$ & $\begin{array}{l}\text { Non-prescribers } \\
(n=13)\end{array}$ \\
\hline \multicolumn{6}{|c|}{ Opioid analgesics/cough mixtures } \\
\hline Never & $36(46.6 \%)$ & $0(0 \%)$ & $0(0 \%)$ & $7(41.2 \%)$ & $8(62.5 \%)$ \\
\hline > once per month & $32(41.6 \%)$ & $0(0 \%)$ & $4(36.4 \%)$ & $7(41.2 \%)$ & $4(30.8 \%)$ \\
\hline$\geq$ once per month & $9(11.7 \%)$ & $3(100 \%)$ & $7(63.6 \%)$ & $3(17.6 \%)$ & $1(7.7 \%)$ \\
\hline \multicolumn{6}{|l|}{ Benzodiazepines } \\
\hline Never & $31(40.3 \%)$ & $0(0 \%)$ & $0(0 \%)$ & $8(47.1 \%)$ & $6(46.2 \%)$ \\
\hline$<$ once per month & $31(40.3 \%)$ & $0(0 \%)$ & $1(9.1 \%)$ & $6(35.3 \%)$ & $7(53.8 \%)$ \\
\hline$\geq$ once per month & 15 (19.5\%) & $3(100 \%)$ & 10 (90.9\%) & $3(17.6 \%)$ & $0(0 \%)$ \\
\hline
\end{tabular}

years; range 6 - 60 years) among GPs, 30.7 years (SD \pm 7.0 years; range 24.0 - 38.0 years) among treatment centre representatives, and 9.1 years (SD \pm 4.0 years; range 4.0 - 15.0 years) among private psychiatrists. State hospital representatives had a mean experience of 12.8 years ( $S D \pm 7.5$ years; range $2.0-27.0$ years).

Training in the management of dependence varied among the different groups. Fourteen (18.2\%) GPs and 3 (17.6\%) state hospital participants reported no training in managing substance dependence, while none of the psychiatrists and treatment centre representatives were in this category. All the treatment centre participants, 8 (10.4\%) GPs and 3 (17.6\%) state hospital representatives reported workplace experience as the source of training, while 10 (90.9\%) psychiatrists indicated academic training as the source of their training. Among GPs, instances of no training were higher in those from the Northern Health Complex $(n=8$; 25.0\%) compared with 3 each in the Eastern (12.0\%) and Southern (15.0\%) Health Complexes, respectively.

\section{Help-seeking for alcohol dependence}

As shown in Table 1, 40.3\% of private GPs were confronted with alcohol dependence on a monthly basis. Only 3 (3.9\%) private GPS in the study reported that they had never been confronted with alcohol dependence. It should be noted that non-involvement was a reason given by 9 of the 14 potential participants who declined to participate.
Healthcare professionals at treatment centres and private psychiatrists had an expectedly high frequency of contact with alcohol dependence. State hospitals showed a varied response, with $17.6 \%$ reporting no contact and $11.7 \%$ reporting a very low level of contact. In comparison with 100\% of treatment centres and private psychiatrists reporting an interaction frequency of more than once per month, state hospitals reported $70.6 \%$.

Although nominated on the basis of their involvement in the treatment of substance dependence, only $53.8 \%$ of the nonprescribers reported monthly or higher frequency of contact with cases of alcohol dependence.

Help-seeking for alcohol dependence was more prevalent at GPs of the Northern and Southern Health Complexes than at the Eastern Health Complex. Fifteen (46.9\%) participants in the Northern Health Complex and 9 (45.0\%) in the Southern Health Complex reported a higher-than-monthly exposure to helpseeking for alcohol, in comparison with 7 (28.0\%) in the Eastern Health Complex.

\section{Help-seeking for cannabis dependence}

From the private GPs' perspective, help-seeking for cannabis dependence was not a common occurrence, with only $11.7 \%$ reporting to see such cases on a regular basis (Table 2). These cases, however, very frequently presented at treatment centres, private 
Table 4. Frequency of help-seeking for cocaine and ecstasy dependence at different groups of professional healthcare practitioners

\begin{tabular}{|c|c|c|c|c|c|}
\hline \multirow[b]{2}{*}{ Frequency } & \multicolumn{5}{|c|}{ Groups of professional practitioners } \\
\hline & $\begin{array}{l}\text { General practitioners } \\
(n=77)\end{array}$ & $\begin{array}{l}\text { Treatment centres } \\
(n=3)\end{array}$ & $\begin{array}{l}\text { Private psychiatrists } \\
(n=11)\end{array}$ & $\begin{array}{l}\text { State hospitals } \\
(n=17)\end{array}$ & $\begin{array}{l}\text { Non-prescribers } \\
(n=13)\end{array}$ \\
\hline \multicolumn{6}{|l|}{ Cocaine } \\
\hline Never & $71(92.2 \%)$ & $0(0 \%)$ & $1(9.1 \%)$ & $11(64.7 \%)$ & $10(76.9 \%)$ \\
\hline$<$ once per month & $5(6.5 \%)$ & $1(33.3 \%)$ & $7(63.6 \%)$ & $6(35.3 \%)$ & $2(15.4 \%)$ \\
\hline$\geq$ once per month & $1(1.3 \%)$ & $2(66.7 \%)$ & $3(27.3 \%)$ & $0(0 \%)$ & $1(7.7 \%)$ \\
\hline \multicolumn{6}{|l|}{ Ecstasy } \\
\hline Never & $70(90.9 \%)$ & $0(0 \%)$ & $1(9.1 \%)$ & $15(88.2 \%)$ & $11(84.6 \%)$ \\
\hline$<$ once per month & $6(7.8 \%)$ & $0(0 \%)$ & $8(72.7 \%)$ & $1(5.9 \%)$ & $1(7.7 \%)$ \\
\hline$\geq$ once per month & $1(1.3 \%)$ & $3(100 \%)$ & $2(18.2 \%)$ & $1(5.9 \%)$ & $1(7.7 \%)$ \\
\hline
\end{tabular}

Table 5. Frequency of help-seeking involving inhalant dependence at different groups of professional healthcare practitioners

\begin{tabular}{|c|c|c|c|c|c|}
\hline \multirow[b]{2}{*}{ Frequency } & \multicolumn{5}{|c|}{ Groups of professional practitioners } \\
\hline & $\begin{array}{l}\text { General practitioners } \\
(n=77)\end{array}$ & $\begin{array}{l}\text { Treatment centres } \\
(n=3)\end{array}$ & $\begin{array}{l}\text { Private psychiatrists } \\
(n=11)\end{array}$ & $\begin{array}{l}\text { State hospitals } \\
(n=17)\end{array}$ & $\begin{array}{l}\text { Non-prescribers } \\
(n=13)\end{array}$ \\
\hline Never & 69 (89.6\%) & $0(0 \%)$ & 10 (90.9\%) & $11(64.7 \%)$ & $6(46.1 \%)$ \\
\hline$<$ once per month & $8(10.4 \%)$ & $3(100 \%)$ & $1(9.1 \%)$ & $3(17.7 \%)$ & $7(53.9 \%)$ \\
\hline$\geq$ once per month & $0(0 \%)$ & $0(0 \%)$ & $0(0 \%)$ & $3(17.7 \%)$ & $0(0 \%)$ \\
\hline
\end{tabular}

psychiatrists and state hospitals. In state hospitals, the level of contacts was on a par with that of alcohol dependence.

\section{Help-seeking for over-the-counter and prescription drug dependence}

Compared with state hospitals, private psychiatrists and treatment centres reported a high frequency of contact with over-the-counter (OTC) and prescription drug dependence. Codeine-containing analgesics were the most common type of analgesic dependence seen across the various referral level environments. A persistently high frequency of contact occurred between private psychiatrists and patients with opioid and other analgesic dependence, while non-prescribers reported a low level of contact (Table 3).

\section{Help-seeking for cocaine and ecstasy dependence}

As seen in Table 4, private psychiatrists reported the highest frequency and widest range of contact with cases involving this category of substances. Cases involving cocaine dependence featured at some state hospitals.

\section{Help-seeking for inhalant dependence}

Inhalant dependence was seen on a regular basis at only $17.7 \%$ of state hospitals, while it did not present at private general medical practitioners to a notable extent. Non-prescribers were more often confronted with cases of inhalant dependence, with 53.9\% reporting a low level of help-seeking (Table 5).

\section{Help-seeking pattern across professional groups}

The ranking of high exposure (once or more per month) showed that alcohol was the most common substance leading to helpseeking, followed by cannabis, across all professional groups (Table 6). Also shown was that OTC/analgesic dependence was more prevalent than cocaine dependence. Help-seeking for inhalant abuse occurred the least in this population.

\section{Discussion}

Our study showed distinct patterns of help-seeking across various professional groups for different substances of abuse, across various geographical areas and across the private and public health sectors. Recent studies on help-seeking investigated factors affecting help-seeking in a population of substance-dependent persons ${ }^{4}$ and young substance-dependent adults. ${ }^{5}$ Myers et al. ${ }^{7}$ reported on the influence of stigmatisation and negative beliefs on helpseeking in historically disadvantaged communities in South Africa? It is, however, impractical to implement a strategy that addresses single variables. The selection of a particular service delivery point reflects the result of a cluster of factors that affect help-seeking, such as patient preference and perceptions, disease factors and available options. In essence, the selection patterns reported in this study reflect the roles played by the various professional groups in dependence within a particular environment, broadly defined by socio-economic factors, medical scheme status and the availability of alternative sources of help. 
Table 6. High exposure patterns of help-seeking for substance dependence across various professional healthcare practitioners

\begin{tabular}{|c|c|c|c|c|c|}
\hline \multirow[b]{2}{*}{ Substance } & \multicolumn{5}{|c|}{ Groups of professional practitioners } \\
\hline & $\begin{array}{l}\text { General practitioners } \\
(n=77)\end{array}$ & $\begin{array}{l}\text { Treatment centres } \\
(n=3)\end{array}$ & $\begin{array}{l}\text { Private psychiatrists } \\
(n=11)\end{array}$ & $\begin{array}{l}\text { State hospitals } \\
(n=17)\end{array}$ & $\begin{array}{l}\text { Non-prescribers } \\
(n=13)\end{array}$ \\
\hline Alcohol & $31(40.3 \%)$ & $3(100 \%)$ & $11(100 \%)$ & $12(70.6 \%)$ & $7(53.8 \%)$ \\
\hline Cannabis & $9(11.7 \%)$ & $3(100 \%)$ & $8(72.7 \%)$ & $1164.7 \%)$ & $4(30.8 \%)$ \\
\hline Analgesics/cough mixtures & $9(11.7 \%)$ & $3(100 \%)$ & $7(63.6 \%)$ & $3(17.6 \%)$ & $1(7.7 \%)$ \\
\hline Benzodiazepines & $15(19.5 \%)$ & $3(100 \%)$ & $10(90.9 \%)$ & $3(17.6 \%)$ & $0(0 \%)$ \\
\hline Cocaine & $1(1.3 \%)$ & $2(66.7 \%)$ & $3(27.3 \%)$ & $0(0 \%)$ & $1(7.7 \%)$ \\
\hline Ecstasy & $1(1.3 \%)$ & $3(100 \%)$ & $2(18.2 \%)$ & $1(5.9 \%)$ & $1(7.7 \%)$ \\
\hline Inhalants & $0(0 \%)$ & $0(0 \%)$ & $0(0 \%)$ & $3(17.7 \%)$ & $0(0 \%)$ \\
\hline
\end{tabular}

Considering that alcohol-dependent subjects were much less likely to seek help than other dependent types, ${ }^{4}$ the persistent low level of help-seeking activity experienced by the group of private GPs (Table 1) demonstrates the importance of the continued involvement of this group of professional healthcare workers. The wide variation in involvement among GPs possibly reflects the influence of individual attitudes of GPs. ${ }^{8}$

The Prevention of and Treatment for Substance Abuse Act (Act no. 70 of 2008) ${ }^{9}$ states that community-based services for substance dependence may only be rendered by individuals registered for such services at the Department of Social Development. Unwillingness of GPS to register and become part of systems suitable for registration as required by the Act ${ }^{9}$ may affect access to treatment and the loss of a potential port of entry into treatment. On the other hand, if state hospitals or treatment centres have to take over this role or expand on their current role, they will need to consider factors that promote help-seeking.

State hospitals served as a point of concentration for cannabis dependence, with similar levels of contact with help-seeking cases involving cannabis dependence (Table 2) and alcohol dependence (Table 1). However, the exposure of state hospital representatives to help-seeking for alcohol dependence was substantially lower (70\%) than that at treatment centres (100\%) and psychiatrists (100\%). When considered together with existing data from the South African Community Epidemiology Network on Drug Use (SACENDU) project reflecting admissions to treatment centres ${ }^{3}$ and the frequencies of alcohol dependence (34\%) and cannabis abusers (2\%) according to national surveys, ${ }^{10}$ there seems to be a deficit in help-seeking for alcohol dependence. However, the context of help-seeking for cannabis is different, with cannabis users presenting with acute psychosis requiring urgent medical intervention.

Psychiatrists, dealing exclusively with dual diagnosis patients, tend to draw a concentration of patients with help-seeking for drugs such as benzodiazepines, cocaine and ecstasy (Tables 3 and 4). This trend could mainly be attributed to the role that these drugs play in the aetiology of psychiatric conditions. Other explanations may be the link with self-medication for underlying psychiatric problems and the greater exposure to benzodiazepines in a higher socioeconomic population. ${ }^{11,12}$

Non-prescribers were mainly involved in the management of alcohol dependence cases. Nearly half of this group had never been confronted by cases of analgesic, cough mixture or sedativehypnotic dependence. They also had a very low frequency of contact with cases of heroin, cocaine and ecstasy dependence. Very often, at the end of a referral line, the non-involvement of therapists, especially in the management of benzodiazepine and hard drug dependence, should be of concern.

The observed patterns also revealed information about particular substance dependencies. A relatively low level of help-seeking for alcohol dependence occurred within a population where alcohol dependence is particularly common, with $27.7 \%$ of men and $13.2 \%$ of women in the Free State scoring more than 2 on the CAGE questionnaire. ${ }^{2}$ The reluctance of alcohol-dependent persons to seek help is a universal phenomenon. ${ }^{4}$

The study further showed that while benzodiazepine and analgesic dependence cases presented to private GPs and psychiatrists, these did not present at state hospitals (Table 3). The frequency of help-seeking at state hospitals for heroin, cocaine and ecstasy dependence (excluding cannabis) was also low (Table 4). These types of dependence therefore seem to be private sector phenomena.

Inhalant dependence cases did not primarily seek help at any of the prescribing groups (Table 5); such dependence therefore did not seem to prompt affected individuals to seek medical advice. The relatively high occurrence of help-seeking for inhalant dependence at non-prescribing therapists remains without explanation.

The higher ranking of OTC/analgesic dependence seen in this study is not reflected by current hard data on treatment 
demand ${ }^{4}$ evidently because these cases generally do not result in treatment. The context of help-seeking should, however, be taken into account. GP participants unanimously indicated that help-seeking for benzodiazepine and analgesics takes the form of 'pseudo-help-seeking' where the doctor is targeted to obtain a legal prescription.

\section{Strengths and weaknesses}

The current study adopted a novel perspective for investigating help-seeking behaviour, viz. various groups of healthcare providers, each representing a particular combination of health service delivery factors. The study demonstrated the context-specific nature of helpseeking for substance dependence. However, these findings, in addition to the relatively small sample size, precluded generalisation of the results. Although the actual size of the gap between treatment need and service delivery cannot be determined, the current study illustrated activity below the radar of formal treatment data.

Regarding future research to address unanswered questions, helpseeking patterns need to be investigated in other populations. Furthermore, factors in health service delivery environments that influence help-seeking behaviour should be explored.

\section{Conclusion}

The observation of help-seeking behaviour from the perspective of healthcare providers expands the view on substance dependence. The study reflected the natural selection of healthcare providers by dependent populations across the spectrum of various substances, and, as such, identified specific professional healthcare groups that can be targeted for implementing substance-specific interventions. The pattern of help-seeking needs to be considered in policies and planning, and provides valuable clues to the factors that promote or hinder help-seeking.

Acknowledgements. We thank all institutions that opened their doors to PMvZ; participants who shared their thoughts; Dr Daleen Struwig, Faculty of Health Sciences, University of the Free State, for technical and editorial preparation of the manuscript; and the Hendrik Vrouwes Trust and the Faculty of Health Sciences, University of the Free State, for funding.

\section{References}

1. Laniel L. Cannabis in Lesotho: A preliminary study. Management of Social Transformations 1998;34. http://www.unesco.org/most/dslaniel.htm (accessed 4 June 2012).

2. Department of Health, Medical Research Council, OrcMacro. South African Demographic and Health Survey 2003. Pretoria: Department of Health, 2007. http://www.doh.gov.za/ www.mrc.ac.za/bod/bod.htm (accessed 5 October 2011)

3. Plüddemann A, Dada S, Parry C, et al. Monitoring alcohol and drug abuse trends in South Africa (July 1996 - June 2008). SACENDU Research Brief 2008;11(2):1-12. http://www. sahealthinfo.org/admodule/sacendu/sacendudec2008.pdf (accessed 5 October 2011).

4. Grella CE, Karno MP, Warda US, Moore AA, Niv N. Perceptions of need and help received for substance dependence in a national probability survey. Psychiatr Serv 2009;60:1068-1074.

5. Fleiss JL. Statistical Methods for Rates and Proportions. 2nd ed. New York: John Wiley and Sons, 1981.

6. Gayman MD, Cuddeback GS, Morrissey JP. Help-seeking behaviours in a community sample of young adults with substance use disorders. J Behav Health Serv Res 2011;38:464-477.

7. Myers B, Fakir N, Louw J. Stigma, treatment beliefs, and substance abuse treatment use in historically disadvantaged communities. Afr J Psychiatry 2009;12:218-222.

8. Deehan A, Taylor C, Strang J. The general practitioner, the drug misuser, and the alcohol misuser: Major differences in general practitioner activity, therapeutic commitment, and 'shared care' proposals. Br J Gen Pract 1997;47:705-709.

9. Department of Social Development The Prevention of and Treatment for Substance Abuse Act (Act No. 70 of 2008). Government Gazette 2009;526(32150):1-37. http://www.info.gov. za/view/DownloadFileAction?id=99550 (accessed 5 October 2011).

10. Peltzer K, Ramlagan S, Johnson BD, Phaswana-Mafuya N. Illicit drug use and treatment in South Africa: a review. Subst Use Misuse 2010;45:2221-2243.

11. Clark RE, Xie H, Brunette MF. Benzodiazepine prescription practices and substance abuse in persons with severe mental illness. J Clin Psychiatry 2004;65:151-155.

12. Brunette MF, Noordsy DL, Xie H, Drake RE. Benzodiazepine use and abuse among patients with severe mental illness and co-occurring substance use disorders. Psychiatr Serv 2003;54:1395-1401. 